\title{
Acceleration of Evaluation, Synthesis and Selection of Engineering Solutions by Morphological Approaches
}

\author{
Dmitry Rakov ${ }^{1, *}$ \\ ${ }^{1}$ Mechanical Engineering Research Institute of the Russian Academy of Sciences (IMASH) Moscow, \\ 101000, Russia
}

\begin{abstract}
The article discussed the issues of creating a decision support system in the design process. It is based on morphological methods and approaches. These approaches can be successfully used to accelerate the evaluation, synthesis and selection of engineering solutions at the conceptual design stage. With the help of combinatorics, it is possible to generate a significant number of different engineering solutions. The conceptual stage is the most important in determining the future parameters and characteristics of the designed systems. The article also considers the possibility of computerization of the morphological approach. All this leads to an increase in the efficiency of the design process as a whole.
\end{abstract}

\section{Introduction}

The tasks of synthesizing engineering solutions (ES) in the conceptual design phase are difficult to formalize. This is true both for the synthesis and analysis of individual innovative engineering systems and for their groups. The following features are typical for innovation [1]:

- Expanding the amount of information that is being considered in the design process. Today it is necessary to take into account the broad connections and relationships of systems, a large number of different professional spheres, which are focused on design activities. This trend is also evident in the creation of multipurpose data banks and automated systems. Complex projects enable multipurpose data applications at different stages of the design, use, and operation process.

- The increasing complexity and mathematical difficulty of engineering calculations in the design process. This trend is manifested by the need for more detailed analysis and modelling of the main components using computer technology. In the field of the application of the theory of computing machines, two areas can be identified - data processing and scientific and engineering calculations.

- The complexity of the design process puts forward the urgent need for its special research, imitation, verification of the possibility of various variants of planned

\footnotetext{
*Corresponding author: rd1@mail.ru
} 
solutions. This raises a set of technical, information and other requirements included in the evaluation activities.

- The predictive side of the project. Design activities should be scientifically and technically sound based on the latest research and development results available here and now. But at the same time, the designer should always take into account the more or less distant future, perspective. In other order, design is increasingly shifting from empirically to the realm of "possible worlds" that can both improve and worsen the situation in our modern world.

\section{Morphological Methodes}

Both intuitive and discursive approaches can be used to solve these problems. Intuitive approaches include brainstorming, synetics, TRIZ and a number of others. The complexity of intuitive approaches lies in the fundamental impossibility of obtaining sustainable, repetitive results. Synonyms such as transformational and non-algorithmic methods are also used in different sources.

In contrast to intuitive methods, there is a group of discursive or algorithmic methods of finding new engineering solutions and predicting their development. The most common morphological methods in this group are morphological [2-4]. These methods can be formalized and their computerization will produce sustainable results.

Computerization of works at the conceptual design stage of the ES will logically complete the software already created and applied at other stages of design.

Computerization will also allow you to solve forecasting problems for specific vehicles or areas of technology.

The software must have the following properties:

- Universality

- Versatility

- Complexity

In developing and justifying decisions, the following data must be available:

- Information about the structure of the system and its elements and the environment;

- Information describing the state of the system and the environment;

- Information on internal and external uncontrolled factors;

- Information about possible scenarios of the development of the ES, changes in the purpose and criteria in the course of its development;

- Information about the management of the vehicle and the ability to adapt to changing environmental conditions.

\section{Supporting Decision-Making and Applications of Morphological Approaches}

In principle, morphological approaches can be seen as analytical systems for supporting decision-making. Features include:

- $\quad$ Generating quality engineering solutions

- $\quad$ Potential computerization and high performance;

- The logic and the possibilities of justifying the choice of certain decisions;

- $\quad$ Versatility and broad specialization;

- The ability to build predictive models,

- Unsustainable to mistakes, 
- $\quad$ Poor-quality inputs cause poor-quality solutions.

In business, the morphological analysis method is used to solve problems and problems in the event of a lack of raw data or to find ideas for new products or services. Methods are also used to solve social problems and solve social problems. Examples of use in an innovative business include:

- $\quad$ Management [5],

- $\quad$ Planning [6],

- $\quad$ Political Studies [7],

- $\quad$ Financial Transactions Simulations [8],

- Decision-making [9],

- $\quad$ Strategies [10],

- $\quad$ Transfer of knowledge [11],

- $\quad$ Market Innovations [12],

- $\quad$ Creating business models [13],

- $\quad$ Prototyping, etc.

\section{Software Development for Morphological Methods}

In order to speed up the search, the Okkam software was developed (Fig.1) [14,15]. Software can be used in the conceptual design phase to increase the innovation of synthesized engineering solutions. In the proposed method, the research is carried out in the following sequence:

- $\quad$ Synthesis of the morphological matrix,

- Determining the system of criteria

- $\quad$ Evaluating options and choosing support options

- Generation

- Choice

- Clustering options based on a similar measure and creating a solution space (Fig. 2),

- $\quad$ Analysis of clusters and solutions with support and converged variants (Fig. 3.4),

- $\quad$ Analysis of project risk, options and choice (Fig. 5),

- $\quad$ Synthesis of predictive models,

- $\quad$ Parametric modeling and optimization.

By comparing the options, the best ones are the best, from which the final table is drawn, where after all the samples there is a set of acceptable solutions. In addition to the composition and functions, the ES also describes the connections. 
Synthese

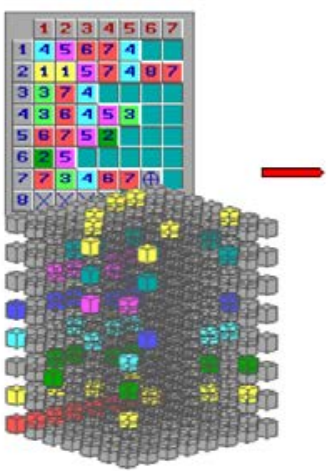

Okkam 2.0.

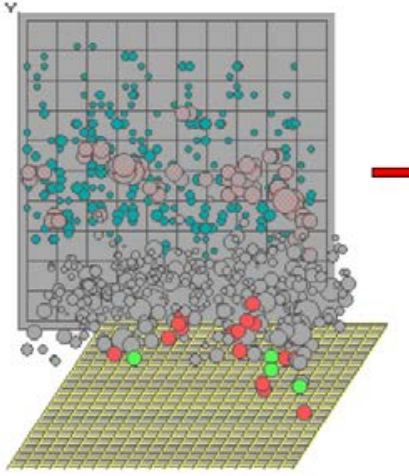

Okkam 3.o.

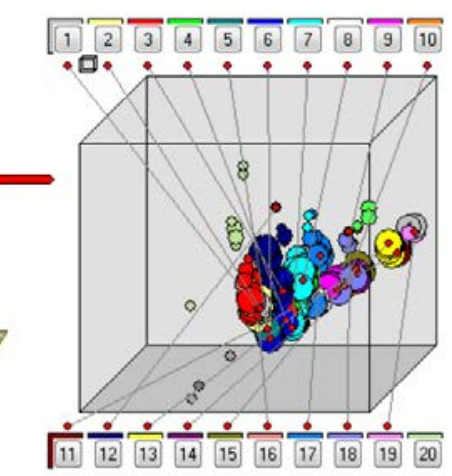

Fig. 1. Software development.

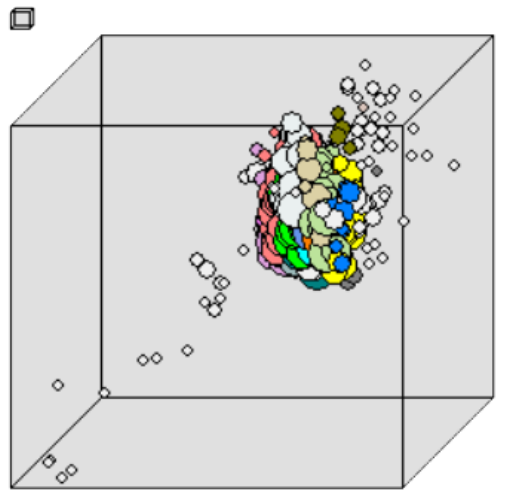

Fig. 2. Clustering options.

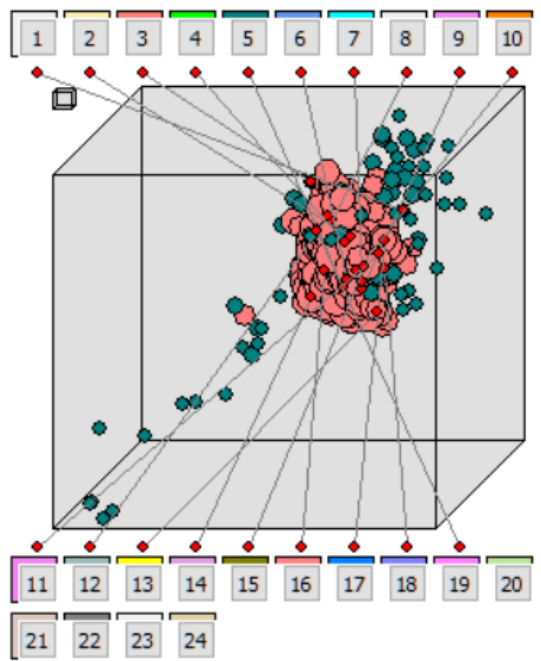

Fig. 3. Clustering options. 


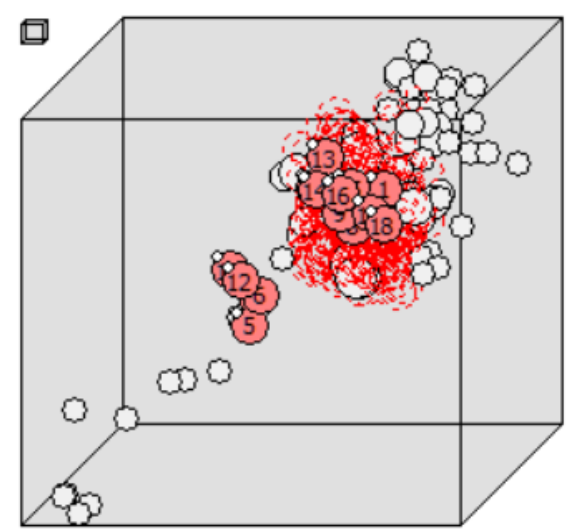

Fig. 4. Reference variants in the solution space.
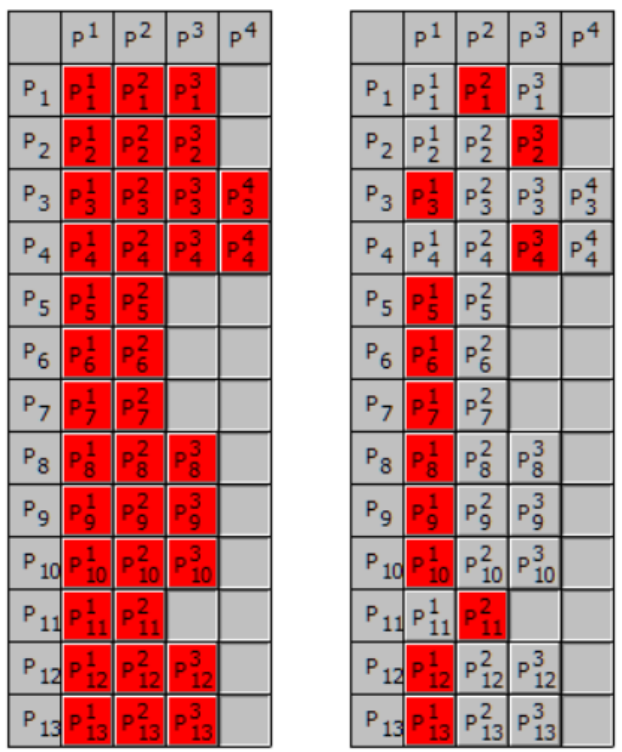

Fig. 5. The version in the morphological matrix.

The main benefits of the software include:

- Improving the creativity of developers. Innovation depends on the number of ideas and their quality. The proposed approach allows you to quickly generate a morphological set of solutions and choose the best.

- Improving the efficiency of the solutions and products being developed. Computer solutions accelerate innovation. They accelerate the processing and dissemination of information, allow for rapid modified of the original data and their dissemination. The time to find information is also reduced.

- Increased competence. Using software, you can track the logic of choosing a solution. This makes the innovation process clearer and easier. In this way, the software allows less competent users to use complex methods at low cost. This increases the level of competence. 
- Accelerate work and decision-making time. In the innovation process, it is important to filter out solutions quickly and efficiently. The software developed has the potential to improve and accelerate decision-making.

- Predictive aspects. The software allows for the rapid development of various scenarios, can quickly change the criteria of evaluation and alternatives. All information is considered at the same time, which improves the quality of decisions made.

\section{Conclusion}

In conclusion, it can be concluded that the use of morphological approaches increases the likelihood of creating innovative solutions. The proposed approach is universal, applicable in many areas and designed to:

- Generating new solutions and ideas,

- Acceleration of evaluation, synthesis and selection of engineering solutions,

- Search for new pioneer solutions and inventions,

- Assessing generated solutions compared to existing,

- Determining the technical level of systems

- Innovation management,

- Patent research and protection,

- Predicting the scientific, technological and innovative development of both individual systems and areas of technology.

\section{References}

1. L. Tondle, I. Paisha. Methodological aspects of system design, Philosophy questions, 2, pp.87-96 (1987)

2. F. Zwicky, Discovery, Invention, Research - Through the Morphological Approach, (Toronto, The Macmillan Company, 1969)

3. F. Zwicky, The Morphological Method of Analysis and Construction, Courant Anniversary Volume, pp. 461-70, (1948)

4. D. Rakov, R. Sukhorukov, M. Pecheykina, Choosing and evaluating fabrication processes by means of a computer-aided innovation support system based on the morphological approach, Journal of Machinery Manufacture and Reliability, 48, 2, pp. 173-178 (2019)

5. A Álvarez, T. Ritchey, Applications of General Morphological Analysis, Acta Morphologica Generalis, 22 (2015)

6. R. Proctor, The Importance of Creativity in the Management Field, British Journal of Management, pp. 2-4 (1991)

7. R. Turley, W. Richardson, J. Hansen, Morphological analysis for health care systems planning, Socio-Economic Planning Sciences (1975)

8. T. Ritchey, Morphology and Policy Analysis. Proceedings of the 16th EURO Conference on Operational Analysis. Brussels (1998)

9. R. Petrusel, L. Mocean, Modeling decisional situations using morphological analysis, Informatica Economica, 4 (2007)

10. A. Sharif, Z. Irani, Applying a fuzzy-morphological approach to complexity within management decision-making, Management Decision, 44 (2006). 
11. J. Kumar, L. Ganesh, Research on knowledge transfer in organizations: a morphology, Journal of Knowledge Management, 13(4) (2009).

12. K. Storbacka, S. Nenonen, Competitive Arena Mapping: Market Innovation using Morphological Analysis in Business Markets, Journal of Business-to-Business Marketing, 19(3) (2012).

13. J. Lee, Y.Hong, A Morphological Approach to Business Model Creation using CaseBased Reasoning. Proceedings of the International Conference on Engineering Design. Denmark: Technical University of Denmark (2011)

14. D. Rakov, Okkam - Advanced Morphological Approach as Method for Computer Aided Innovation (CAI), MATEC Web of Conferences 298, ICMTMTE 2019, 00120 (2019)

15. A. Bardenhagen, D. Rakov Advanced morphological approach in aerospace design during conceptual stage, Facta Universitatis. Series: Mechanical Engineering, 17, pp. 321-332 (2019) 